\title{
El ordenamiento \\ del territorio urbano \\ y rural: imperativo \\ para garantizar igualdad en los territorios
}

Jorge Eduardo Camargo Carvajal ${ }^{1}$

Andrea Lizcano Noguera ${ }^{2}$

\section{RESUMEN}

La población campesina en Colombia enfrenta una alta desigualdad en materia de acceso y garantía de los derechos, situación que se debe en parte a que no se ha realizado la reforma agraria. El Gobierno nacional, en el marco del Acuerdo de Paz con la FARC, pactó como una de las bases para la consolidación de la paz la necesidad de hacer una reforma rural integral, por lo que parte del éxito de la implementación de cada uno de los acuerdos está en la ordenación del territorio rural y la participación en este de los campesinos.

1 Abogado, especialista en Derecho Administrativo, Universidad Santo Tomás de Aquino, Bucaramanga, Colombia. Especialista en Derecho del Medio Ambiente y en Servicios Públicos Domiciliarios, Universidad Externado de Colombia, Bogotá, Colombia. Defensor delegado para Asuntos Agrarios y Tierras, Defensoría del Pueblo, Bogotá, Colombia ; exprocurador judicial II Ambiental y Agrario de Santander, Bucaramanga, Colombia. Correo-e: jorgecamargo@defensoria.gov.co.

2 Abogada de la Universidad del Meta, Villavicencio, Colombia. Magíster en Derechos Humanos y transición a la Democracia, Universidad Externado de Colombia, Bogotá, Colombia. Asesora de la Delegatura para Asuntos Agrarios y Tierras, Defensoría del Pueblo, Bogotá, Colombia, exdirectora territorial del Meta-Unidad de Restitución de Tierras, Villavicencio, Colombia. Correo-e: alizcano@defensoria.gov.co. Fecha de recepción: 30 de abril de 2018. Fecha de modificación: 10 de mayo de 2018. Fecha de aceptación: 20 de mayo de 2018. Para citar el artículo Camargo Carvajal, Jorge Eduardo y Lizcano NoGUERA, ANDREA, "El ordenamiento del territorio urbano y rural: imperativo para alcanzar igualdad en los territorios", Revista digital de Derecho Administrativo, Universidad Externado de Colombia, n. ${ }^{\circ}$ 20, 2018, pp. 455-463. DOI: https://doi.org/10.18601/21452946.n20.16. 
Palabras clave: Ordenamiento territorial, Población campesina, Acuerdo de paz, Ruralidad, Reforma agraria.

\title{
Land Use Planning of the Urban and Rural Territory: A Condition to Guarantee Equality in the Territories
}

\begin{abstract}
The rural population in Colombia faces a high inequality in the access and guarantee of rights, due to some extent to the fact that a reform of the rural land has not been carried out. The national government, within the framework of the Peace Agreement with the FARC, agreed to a comprehensive reform of the tenure and use of rural land. A well-organized, transparent and inclusive reform of the rural land is therefore a condition for a successful implementation of the peace agreement.
\end{abstract}

Keywords: Land Use Planning, Rural Population, Peace Agreement, Rurality, Rural Land Reform.

A propósito de los veinte años de la Ley 388 de 1997 de ordenamiento territorial, la Defensoría del Pueblo, desde la Delegatura para Asuntos Agrarios y Tierras, tuvo la oportunidad de participar en la conmemoración que realizó el Departamento de Derecho Administrativo de la Universidad Externando mediante una ponencia en la cual destacó la imperiosa necesidad de armonizar el desarrollo urbano con el rural. Lo anterior, con ocasión de las recientes cifras del censo nacional agropecuario que reflejan la alta desigualdad entre estos dos territorios y del Acuerdo de Paz firmado con las FARC, donde en el primer punto se acordó hacer la reforma rural integral para disminuir esta desigualdad.

Si bien el país entero sigue afrontando las consecuencias de un conflicto armado de duración prolongada, es en las zonas rurales donde más se sienten y han sentido sus consecuencias y el impacto negativo para su desarrollo y el de sus pobladores. Es así que resulta de interés analizar si el punto uno del Acuerdo de $\mathrm{Paz}$, para implementar la tan anhelada Reforma Rural Integral, puede mejorar esos índices de desigualdad que existen entre los territorios urbano y rural a través de las apuestas pactadas para el desarrollo rural, toda vez que el ordenamiento territorial es un pilar base para lograr este objetivo.

Para adentrarnos en este análisis, es importante comenzar por hacer una referencia a la situación socioeconómica de los pobladores rurales versus los pobladores urbanos en zonas afectadas por el conflicto armado, para seguidamente observar el panorama de la situación de los campesinos y determinar 
por qué es imperativo hacer del ordenamiento territorial un instrumento para disminuir la brecha de desigualdad. Por último, se plantean algunas ideas y recomendaciones para que los ejercicios de ordenamiento social y productivo de la propiedad realmente impacten en las zonas rurales en armonía con las zonas urbanas.

\section{ALGUNAS CONSIDERACIONES SOBRE LA SITUACIÓN SOCIOECONÓMICA DE LA POBLACIÓN RURAL Y LOS CAMPESINOS EN COLOMBIA}

La situación socioeconómica de los pobladores de zonas rurales y la de los pobladores de zonas urbanas es, sin duda, asimétrica: los primeros, históricamente, han vivido bajo presiones sobre sus tierras que los han llevado a migrar de un lugar a otro por causas como la pobreza, la crisis económica o el conflicto armado; los segundos, en cambio, aunque enfrentan igualmente problemas económicos y algunas afectaciones puntuales por el conflicto armado, han tenido la ventaja de vivir en los centros urbanos donde han contado con mayores facilidades de acceso a servicios públicos, salud, educación, empleo y oferta de vivienda.

Las cifras del DANE confirman dicha asimetría, si vemos por ejemplo el índice de necesidades básicas insatisfechas (NBI) del año 2005 en un municipio como Medellín, capital de Antioquia, era de 12,33\%, pero en este mismo departamento, el municipio de Turbo, zona fuertemente afectada por el conflicto armado y con precarias vías e infraestructura, el NBI era del 57,49\%. Ahora, pasados diez años desde que se hizo dicha medición, este panorama no ha variado mucho según la valoración del índice de pobreza extrema que actualmente aplica el DANE, donde, en general, en los centros urbanos, en 2016, el índice de pobreza extrema fue de 5,6\%, mientras en las zonas rurales dispersas era de $18,1 \%$, lo que denota una diferencia de $12,5 \%$ entre lo urbano y lo rural. En el mismo sentido, el Censo Nacional Agrario de 2014 entregó una serie de cifras que revalidan la situación de desigualdad descrita. Según las cifras conocidas, el $87,36 \%$ no tiene infraestructura en sus predios para facilitar la productividad, el $66,7 \%$ no usa sistemas de riego, el $83,9 \%$ no cuenta con maquinaria, el $83,5 \%$ no recibe asistencia técnica y el $89,3 \%$ no solicita crédito. La precariedad de las condiciones en que laboran nuestros campesinos, es, pues, manifiesta y preocupante.

En efecto, estas cifras ratifican que las zonas rurales del país, pese a su riqueza en tierras, biodiversidad, recursos mineros, hídricos, materias primas y capacidad productiva, tienen los índices más altos de pobreza, por lo que se hace necesario impulsar una reforma agraria que impacte a esta población y mejore sus condiciones de vida, y así mismo, pensar e implementar medidas de desarrollo rural que beneficie a sus pobladores más vulnerables, que son los campesinos pobres. 


\section{EL ORDENAMIENTO TERRITORIAL COMO UN INSTRUMENTO DE CORRECCIÓN Y NIVELACIÓN DE LAS DESIGUALDADES}

La situación descrita en el apartado anterior pone de manifiesto que es necesario hacer efectivo el ordenamiento territorial en lo rural, ya que en la mayoría de las zonas urbanas existen avances en esta materia gracias a la implementación de la Ley 388 de 1997 y otras leyes anteriores, que se expidieron con el fin de ordenar las urbes para proveer servicios públicos y mejorar la calidad de vida de sus habitantes. Por el contrario, "la gran mayoría del país no ha empezado a pensar cómo debe funcionar el Plan de Ordenamiento Territorial Rural (РОт). La desorientación que tienen las entidades territoriales sobre el particular es enorme" ${ }^{\prime \prime}$.

Es así que en la exposición de motivos de la Ley 388 se indicó que "el intervencionismo estatal debe encaminarse hacia el ordenamiento y reordenamiento urbano y a proveer los bienes y servicios que mejoren la calidad de vida de la sociedad. Concebir que el crecimiento económico y las fuerzas del mercado, por sí solas, pueden solucionar los problemas ecosociales, físicos y ambientales, es un craso error". Esta afirmación se sostuvo bajo el argumento que el país era más urbano que rural, ya que en las capitales de los departamentos habitaba el $45,36 \%$ del total de la población ${ }^{4}$. En parte tenían razón, porque en esta época se presentaron los picos más altos de desplazamiento forzado por disputa entre paramilitares y la guerrilla, lo que ocasionó el conocido éxodo de campesinos a las urbes. Sin lugar a dudas, como lo resalta el Informe de Desarrollo Humano de 2011, el modelo de desarrollo y la modernización han ignorado y desvalorizado lo rural, porque han visto a los conglomerados urbanos como la opción más viable para alcanzar el progreso y mejorar los niveles de vida ${ }^{5}$.

En consecuencia, esa falta de ordenamiento del territorio rural en muchos municipios del país, en parte, facilitó los despojos de tierras, la apropiación indebida de baldíos de la nación, la ocupación indiscriminada de áreas de especial importancia ambiental como parques nacionales naturales, el desecamiento de ciénagas y la tala de árboles en zonas de importancia hídrica. La desactualización del catastro, la falta de claridad sobre las figuras de ordenamiento territorial, la indefinición y desconocimiento de los linderos de las áreas protegidas y los territorios étnicos, y la poca presencia institucional han sido, sin duda, causa efectiva de esta triste realidad, que es el común denominador de la mayor parte de zonas rurales del país. La carencia de un ordenamiento 
territorial en lo rural no es más que la evidencia no solo de falta de gobierno del territorio, sino, más aún, de la ausencia de Estado, sus bienes y servicios fuera de nuestras zonas urbanas.

\section{3. ¿ES POSIBLE UN ORDENAMIENTO SOCIAL Y PRODUCTIVO DE LA PROPIEDAD QUE IMPACTE EN LAS ZONAS RURALES Y CONTRIBUYA A ELEVAR SU NIVEL DE VIDA A UN PUNTO SIMILAR AL DE LAS ZONAS URBANAS?}

Por fortuna, la mirada de una Colombia netamente urbana, por muchos años imperante, ha venido cambiando después de hechos históricos como el paro agrario de 2014, originado "única y exclusivamente a causa del incumplimiento del Gobierno Nacional con los acuerdos pactados en el 2013 con las organizaciones campesinas movilizadas, así como también, por la ausencia de una ruta que corrija los problemas crónicos de la política pública agropecuaria" ${ }^{\text {. }}$.

Para esto, los campesinos y las minorías étnicas, en distintos espacios de diálogo con el Gobierno, expusieron su situación y pidieron ser incluidos en las políticas públicas con enfoque rural, ampliar la inversión de recursos y ser partícipes de la planeación de sus territorios, para así definir un modelo de desarrollo rural que les impacte favorablemente y disminuya la gran brecha de desigualdad en que existe entre las urbes y el campo.

En sintonía con estos compromisos del Gobierno y las comunidades campesinas y étnicas, en el punto 1 para la Reforma Rural Integral se reconoció igualmente la necesidad de hacer una política pública especial para el campo, que comprenda el acceso a tierras, la conformación de un fondo de tierras por 3 millones de hectáreas, la formalización de la propiedad rural, la creación de una jurisdicción agraria, la actualización del catastro, el diseño de planes de desarrollo con enfoque territorial y planes nacionales sectoriales, el cierre de la frontera agrícola, las Zonas de Reserva Campesina y la ordenación productiva y ambiental del territorio.

Por consiguiente, las apuestas del punto uno necesitan, para poder avanzar en su implementación, del ordenamiento territorial, entendido este como

la sintonía político-administrativa entre población, territorio y gobierno. La Planeación es una técnica que, como la arquitectura, ordena espacios. El ejercicio del Ordenamiento Territorial, correlaciona tres elementos: territorio, uso de la tierra y administración pública. El territorio es el primer dato, la naturaleza lo ordena por sí misma. La población es la protagonista del Ordenamiento, establece usos

6 I. Penagos, Paro Agrario 2014: Radiografía del presente y futuro de la protesta campesina. Disponible en línea http://palabrasalmargen.com/edicion-34/paro-agrario-2014-radiografia-delpresente-y-futuro-de-la-protesta-campesina/ [consultado el 16 de febrero de 2018]. 
de la tierra. El uso de la tierra es la destinación que la población le da al territorio en ejercicio de sus actividades. La administración pública es el agente ordenador para lo cual utiliza la planeación ${ }^{7}$.

Adicionalmente, se deben tener claros los objetivos hacia los cuales debe tender el ordenamiento social de la propiedad en el marco de la implementación del Acuerdo de Paz. Siguiendo lo planteado por Reyes Posada, estos son cuatro:

Primero, el imperativo ambiental, para proteger los ecosistemas afectados y minimizar el impacto del cambio climático en las poblaciones más vulnerables por la deforestación de las selvas y la sobreexplotación del suelo por el sobre poblamiento de algunas áreas con respecto de su capacidad productiva y prácticas agrícolas inadecuadas. El ordenamiento ambiental debe cerrar la expansión de la frontera agrícola en reservas forestales selváticas, amazónicas y pacíficas, establecer un grado de pendiente de las tierras aptas para la producción y delimitarse los humedales y las zonas de descarga hídrica para evitar inundaciones.

Segundo, la eficiencia económica. Que es hacer uso adecuado de la tierra, para lo cual deben valorarse sus funciones sistémicas fundamentales para mantener productivo el conjunto de territorios, en términos de conservación, restauración y uso adecuado del potencial productivo.

Tercero, la justicia distributiva, fundada en la equidad para dar acceso a la tierra a los productores agrarios que carecen de tierra o poseen poca. Distribuir buenas tierras cercanas a mercados y dotadas con bienes públicos es una política más eficiente para destinar ingresos y oportunidades que la alternativa tradicional que es llevar infraestructura costosa donde se expande la frontera agrícola.

Cuarto y último objetivo, es establecer condiciones institucionales que fortalezcan la paz, para poder resolver conflictos territoriales entre campesinos y los propietarios de las tierras ${ }^{8}$.

El ordenamiento del territorio rural es, pues, una necesidad sentida de nuestras zonas rústicas y un elemento indispensable para la materialización de los compromisos de la Reforma Rural Integral y, desde luego, de la propia Constitución, que en numerosas disposiciones remite a las autoridades la responsabilidad de velar por la gestión adecuada del suelo y los recursos naturales, como vía fundamental para asegurar el mejoramiento de la calidad de vida de la población.

7 A. Mendoza, "Ordenamiento territorial y planeación", Boletín de la Sociedad Geográfica de Colombia, n. ${ }^{\circ} 127$, vol. 43, p. 198. Disponible en línea https://www.sogeocol.edu.co/documentos/ord_territ.pdf [consultado el 1. ${ }^{\circ}$ de febrero de 2018].

8 Alejandro Reyes Posada, La reforma rural para la paz, Bogotá: Penguin Random House, 2016 


\section{ALGUNAS RECOMENDACIONES FINALES}

La Defensoría presenta algunas recomendaciones para que los ejercicios donde se planee el ordenamiento social y productivo de la propiedad realmente impacten a las comunidades rurales por medio de la correcta implementación de la Reforma Rural Integral. Es así que para ejecutar cada una de las apuestas del acuerdo, el ordenamiento territorial es una requisito básico, ya que en los territorios priorizados y agrupados en 16 zonas que cubren 170 municipios se hará a través de un plan de desarrollo con enfoque territorial (PDET), que a su vez deberá aterrizar sus acciones en un plan de acción para la transformación regional (PATR), según lo establecido en el Decreto 893 de 2017.

Por lo anterior, la formulación de los planes de desarrollo con enfoque territorial para la Reforma Rural Integral debe cumplir lo establecido en el artículo 6 del mencionado decreto, que ordena su armonización y articulación con los planes de desarrollo y los planes de ordenamiento territorial. Esto garantiza que los PDET no desconozcan lo planeado y priorizado por los municipios, pero con la claridad que ahora esta planeación del territorio debe hacer una especial consideración de la ruralidad, reconociendo que las zonas rurales deben ser objeto de una planeación y ordenación presidida por una visión diferente a la urbana, acorde con las particularidades y necesidades de lo rural.

Del mismo modo, es necesario que las comunidades, por medio de sus representantes, conozcan los planes de ordenamiento territorial de sus municipios, ya que no tenerlos en cuenta en la formulación de los PDET y los PART puede llevar a la planeación de acciones que por las condiciones físicas o jurídicas de un territorio resulten inviables o, peor aún, inútiles.

Se impone reconocer por quienes participen en la formulación de los PDET, lo que la Corte Constitucional dejó sentado en la sentencia C-077 de 2017, donde estudió la constitucionalidad de la Ley 1776 de 2016 (ZIDRES), sobre la importancia del campesino, llamando la atención ampliamente sobre la vulnerabilidad y los riesgos que tiene que afrontar un ciudadano que habita en la ruralidad y, a su vez, destaca la importancia del campo y el campesino para el desarrollo del país.

Además, para lograr cerrar la desigualdad entre el campo y la ciudad, es necesario cambiar la visión de la tierra. Esta no debe seguir siendo solo un factor económico para acumular riqueza o acceder al control social y político de una región. Debe ser entendida como ese espacio donde el país tiene la oportunidad de implementar un modelo de desarrollo agrario que de cabida no solo a los grandes productores de la industria del agro, sino también a los medianos y pequeños productores por medio de agricultura familiar. Un espacio para la equidad y la diversidad.

Ligado a esto está el proceso de reconocimiento del campesino por toda la sociedad colombiana como el principal sujeto para la planeación de acciones de toda la institucionalidad enfocada en las zonas rurales. Ser campesino 
no debería ser visto como una actividad económica, sino como un grupo poblacional con tradición, cultura, arraigo a la tierra y sobre el cual está sustentada parte de la historia de este país y la pervivencia de sus habitantes como guardines de la seguridad alimentaria. Por ello, las organizaciones campesinas han pedido al DANE que incluya en el censo de población la categoría de campesino, para saber cuántos son realmente y poder plantear, a partir de la información recogida, políticas públicas eficaces para desarrollo social y humano.

Para todo esto, es necesario que el ordenamiento del territorio rural no sea entendido ni planificado por separado de lo urbano. Por el contrario, tiene que ser visto como un sistema, donde lo que pasa en un territorio indiscutiblemente afecta el otro. El claro ejemplo de esto son las migraciones que se dan de pobladores rurales a las grandes ciudades producto de crisis económicas, afectaciones ambientales o el conflicto armado, cuyos efectos se padecen en las ciudades a las que esta población llega en búsqueda de un espacio físico y de una oferta de servicios y acceso a derechos como salud, educación, empleo o vivienda. En el plano ambiental otro ejemplo claro de dicha interrelación se encuentra en los efectos negativos del no control sobre las áreas que protegen las fuentes hídricas, que proveen agua a todos los habitantes de un municipio y también son necesarias para regar los cultivos de alimentos que llegan a las ciudades. Sus secuelas negativas golpean por igual a las poblaciones urbanas, que a las campesinas.

El ordenamiento social y productivo de la propiedad rural, los planes de ordenamiento territorial y los planes de desarrollo con enfoque territorial deben hablarse y articularse para lograr una mirada del territorio más amplia e incluyente, que impacte en políticas públicas exitosas que garanticen los derechos de las poblaciones más vulnerables tanto en lo urbano como en lo rural.

\section{BIBLIOGRAFÍA}

Mendoza, A. "Ordenamiento territorial y planeación", Boletín de la Sociedad Geográfica de Colombia, n. ${ }^{\circ}$ 127, vol. 43, 1p98. Disponible en línea https://www.sogeocol.edu. co/documentos/ord_territ.pdf. [Consultado el 1. ${ }^{\circ}$ de febrero de 2018].

Penagos, I. Paro Agrario 2014. Radiografía del presente y futuro de la protesta campesina. Disponible en línea http://palabrasalmargen.com/edicion-34/paro-agrario-2014-radiografia-del-presente-y-futuro-de-la-protesta-campesina/. [Consultado el $16 \mathrm{de}$ febrero de 2018].

PNUD, Colombia rural. Razones para la esperanza. Informe de Desarrollo Humano 2011, Bogotá: PNUD, 2011. 
Restrepo, Juan Camilo. La cuestión agraria. Tierra y posconflicto en Colombia, Bogotá: Editorial Debate, 2014.

Reyes Posada, Alejandro. La reforma rural para la paz, Bogotá: Penguin Random House, 2016. 